\title{
The Effect of Poly-Ethylene-co-Glycidyl Methacrylate Efficiency and Clay Platelets on Thermal and Rheological Properties of Wood Polyethylene Composites
}

\section{Ansou Malang Badji ${ }^{*}$, El Hadj Babacar Ly¹, Diene Ndiaye1, Abdou Karim Diallo1, Ndickou Kebe1, Vincent Verney ${ }^{2,3}$}

${ }^{1}$ Applied Physic Department, Gaston Berger University, Saint-Louis, Senegal

${ }^{2}$ Institut de Chimie de Clermont-Ferrand, Université Blaise Pascal, Clermont-Ferrand, France

${ }^{3}$ CNRS, UMR 6296, ICCF, Université Blaise Pascal, Aubière, France

Email: ^ansouba2014@gmail.com

How to cite this paper: Badji, A.M., Ly, E.H.B., Ndiaye, D., Diallo, A.K., Kebe, N. and Verney, V. (2016) The Effect of PolyEthylene-co-Glycidyl Methacrylate Efficiency and Clay Platelets on Thermal and Rheological Properties of Wood Polyethylene Composites. Advances in Chemical Engineering and Science, 6, 436-455.

http://dx.doi.org/10.4236/aces.2016.64040

Received: July 24, 2016

Accepted: October 9, 2016

Published: October 12, 2016

Copyright $\odot 2016$ by authors and Scientific Research Publishing Inc. This work is licensed under the Creative Commons Attribution International License (CC BY 4.0).

http://creativecommons.org/licenses/by/4.0/

\section{(c) (i) Open Access}

\begin{abstract}
Global ecological concerns have resulted in an interest in renewable natural materials. Composites based on high density polyethylene (HDPE), wood fiber (Veneer) and containing coupling agents like nanoclay (NC) and poly-ethylene-co-glycidyl methacrylate (PEGMA) were made by melt compounding and then injection molding. In this study, the effects of two variable parameters namely nanoclay and coupling agent on the rheological and thermal properties of wood polyethylene composites (WPECs) were investigated. The study investigates the morphology phase, rheology behaviors and thermal properties by scanning electron microscope, capillary rheometer and thermal gravimetric analyzer. The SEM micrographs of the composites showed that the outer surfaces of the wood were coated by a section of amorphous lignin. The state of dispersion in HDPE/pine/clay composites was improved by EGMA because it could interact with pine flour in addition to clay. The interaction of reinforcement with coupling agent and HDPE matrix is strong based on the observation of the fracture surface of composites when EGMA is present. However the addition of $2.5 \%$ clay slightly lowered the initial degradation temperature $\left(\mathrm{T}_{\mathrm{d}}\right)$ but did not improve the thermal stability. Obviously, all the composites materials exhibit viscoelastic values greater than those of neat HDPE.
\end{abstract}

\section{Keywords}

Wood HDPE Composite, Rheological and Thermal Properties, Microscopy, TGA 


\section{Introduction}

The scarcity of fossil resources, the growing concerns about the environment, and the ever increasing prices of petroleum-based materials are some of the driving forces towards the exploitation of renewable and eco-friendly materials. Polymer blending is an attractive alternative for producing new polymeric materials with desirable properties without having to synthesize a totally new material. These products are used in the construction and automotive industry in many developed and developing countries. The wood fibers can easily return to the cycle of nature and the production costs are significantly lower. In recent years, polymer/layered silicate (i.e. clay) nanocomposites have attracted great interest, both in industry and in academia, because they often exhibit remarkable improvement in material properties when compared with virgin polymer or conventional micro and macro composites.

These improvements can include high moduli [1], increased strength and heat resistance [2], decreased gas permeability [3], flammability [4], and increased biodegradability [5]. The use of wood polymer composite for the manufacturing of structural materials has incited a renewed interest in recent years, especially in the construction materials sectors and in the automotive industry. This enthusiasm is explained by environmental and economic considerations. In addition, the utilization of recycled plastic and waste wood in the manufacturing of such composites may help the environment by reducing the land filling and/or promoting the recycling. These initiatives that limit human impact on the environment and reducing dependence on oil are environmentally welcome. In this context, the composites based on natural fibers are developed to replace some conventional composites synthetic fibers. Organic hybrid materials have received substantial attention due to their wide range of applications resulting from the properties imparted by the organic particles. Wood fiber is available worldwide and is biodegradable. Among the inorganic layered materials, layered silicates are often used for inclusion in the hybrids due to their ability to intercalate and exfoliate at the nanoscale in the thermoplastic matrix. Cloisite is the popular commercial nanoclays (NC) available in the market; clay filled polymers are widely used in packaging applications due to the ability of clay platelets to reduce permeability of penetrants through the polymer materials [6] [7]. Surface modified nanoclays (NC) are widely used in technological applications [8], because of their improvement of strength [9] [10], modulus, controlled biodegradability, and water vapor transmission resistance [11], which are dependent on the degree of dispersion of inorganic phase in polymeric matrix [12]. HDPE was selected as a matrix because HDPE/wood composites account for about $80 \%$ of the natural fiber/thermoplastic composites market [13]. In the reinforcement of HDPE matrix with nanoclay, Omar Faruk et al. [14] have demonstrated that the melt blending process, in which nanoclay/HDPE nanocomposite was used as matrix, appeared to be the best approach of incorporating nanoclay in WPCs. Other advantages for polymer blends are versatility, simplicity, and inexpensiveness. Compatibilization is

one of the most important factors which play a prominent role in WPC. Properties such as mechanical, thermal and water uptake are strongly dependent on the compati- 
bility within the composite [15]. Different types of compatibilizers such as glycidyl methacrylate (GMA), PE grafted GMA, maleic anhydride grafted PE, PP grafted maleic anhydride, etc., are widely used to enhance the compatibility among different polymers and wood fiber (WF) [16] [17]. The homopolymer and copolymer based on glycidyl methacrylate belong to the class of potential functional polymers. These compatibilizers can interact with the hydrophobic polymer and hydrophilic WF through their long olefinic chain and through their glycidyl or anhydride group. This leads to an improvement in the interfacial adhesion between the polymers and WF, resulting in an enhancement of the properties of composites. However, there are some shortcomings of natural fibers, which affect their reinforcing capabilities. Natural fibers have a tendency to absorb moisture due to their hydrophilic nature, as well as forming aggregates during processing. These drawbacks, like water uptake, moisture and incompatibility with the hydrophobic polymer matrix, the tendency to form aggregates during processing and the low resistance to moisture, reduce the potential of using natural fibers as reinforcement in polymers [18] [19]. In addition, their thermal stability (start degrading above $200^{\circ} \mathrm{C}$ ) limits their utilization in certain polymer matrices. Presence of hydroxyl groups in natural fibers makes them hydrophilic in nature and this generates high moisture absorption that causes composites to fail in wet condition through fiber swelling and delamination [20] [21]. In fact, when particulate filler is dispersed into a polymer melt, it is quite difficult to achieve a strong bond between particles and matrix. A possible reason, among others, is the poor wettability of the fine filler particles by the polymer melt, especially with non-polar, high melt viscosity thermoplastics. The incompatibility may cause problems in the composite processing and in the materials properties. The highly polar character of natural fibers has inherently low compatibility with nonpolar polymer matrices, especially hydrocarbon matrices such as polypropylene (PP) and polyethylene (PE) [18]. As a result, the polymer matrix is unable to transfer the stress to the filler through the interface when submitted to mechanical load, being the reinforcement efficiency reduced. The poor resistance for water absorption restricts the use of natural fibers in many structural and out-doors applications. The main solutions found to improve compatibility moisture are the use of coupling agents, pretreatment of wood fiber and/or the polymer through surface coating treatment or graft copolymerization which improves mechanical properties, water absorption and dispersion [22] [23]. The most commonly used compatibilizer in WPEC is usually polyethylene grafted with maleic anhydride (MAPE) [24]. The functional groups of these polymers were shown to interact strongly or even react chemically with the surface of wood [25], while the long alkyl chains diffuse into the matrix making stress transfer possible. The EGMA can interact with the hydrophobic polymer and the hydroplilic wood fibers through their long olefinic chain and through their glycidyl group [26]. Recently, investigations have shown that the mechanical properties of wood polyethylene composites modified with maleic anhydride, presented an increase of overall crystallinity compared to the pure and unmodified polyethylene [27]. The hypothesis to explain this phenomenon is the nucleation of crystallites [28]. In accordance with literature information, interfacial adhesion plays a crucial role in the determination of com- 
posite properties and the introduction of coupling agent has a significant effect. Adding a small amount of nanoclay (usually $\leq 5 \mathrm{wt} \%$ ) can dramatically improve mechanical properties, thermal and dimensional stability, flame retardance, barrier properties, and many other such properties [29] [30].

The key to yield these improved properties is exfoliating and completely dispersing individual platelets with high aspect ratios throughout the polymer matrix. The use of clay instead of MAPE is interesting in terms of the fire retardancy of the WPCs, which tend to burn quite easily; this is a heavy drawback. Although the influence of the surface treatment of wood flour with EGMA on the strength properties of WPCs has been extensively investigated [31] [32]. Little information is available in the open literature on the effect of combining EGMA with nanoclay on the morphological, viscoelastic and rheological properties of WPCs. Rheology has been widely used to assess the morphology and interfacial status of polymer blends, alloys and filled polymers [33] [34] but effective rheological methods have not yet been explored to evaluate wood filler dispersion and interfacial status. Increased viscosity and shear thinning was reported for wood fiber filled polyethylene [35]. Nanocomposite technology with organophilic layered silicate as in situ nano reinforcement offers new opportunities for improved wood properties. Therefore, in this study, we examined the effects of combining EGMA and nanoclay (NC), as a coupling agent on these properties of the WPCs. In this work, in order to investigate those properties of the composites, the morphology phase, scanning electron microscope (SEM), capillary rheometer, and thermal gravimetric analyzer (TGA) respectively were used to investigate the properties sub-mentioned. Microscopy is used to analyze the improved compatibility and the morphologies of filler particles in WPCs [36]. Systematic studies on the amount of coupling agent, cross linking agent and NC are vital to understand their functions in wood composite improvements. In the present investigation, a parallel plate rotational rheometer is used to characterize rheological composites made by HDPE and wood fiber with and without coupling agent. Indeed, the incompatibility between the wood, hydrophilic in nature and polymers, generally hydrophobic, is the main difficulty of manufacturing of wood-polymer composites.

\section{Experimental}

High density polyethylene (HDPE) has been used in the wide range of engineering field due to his good physical and mechanical properties. Polyethylene is one of the most versatile commercial polymers, with its semi-crystalline nature allowing processing in a broad temperature range. The crystalline phase of the polymer provides resistance, while the amorphous phase provides flexibility [37]. HDPE is the most commonly used polymer matrix for WPCs because of its relatively low processing temperature and good processability [38]. (HDPE) was provided as granules by Nova Chemicals. Its melt flow index was $7.0 \mathrm{~g} / 10 \mathrm{~min}$ at $190^{\circ} \mathrm{C}$ and density at room temperature was 0.962 $\mathrm{g} / \mathrm{cm}^{3}$. The compatibilizer ethylene-co-glycidyl methacrylate (EGMA) pellets with melt index $5 \mathrm{~g} / 10 \mathrm{~min}\left(190^{\circ} \mathrm{C} / 2.16 \mathrm{~kg}\right)$ was procured from EGMA, Arkema Inc. Philadelphia, PA, USA. EGMA was used as a compatibilizer. It has a density of $0.93 \mathrm{~g} \cdot \mathrm{cm}^{-3}$, a melting 
point of $93^{\circ} \mathrm{C}$, a tensile strength of $12 \mathrm{MPa}$, and an elongation at break of $44 \%$. The most widely used clay mineral for polymer-clay nanocomposites is montmorillonite. The exfoliated clay structure possesses superior properties and gives a few advantages over other nano fillers like in terms of cost and environmental friendly matters [39] [40]. Montmorillonite modified with a dimethyl-dehydrogenated tallow, quaternary ammonium with CEC $125 \mathrm{meq} / 100 \mathrm{~g}$ clay, density $1.66 \mathrm{~g} / \mathrm{cc}$, and d-spacing $\mathrm{d}_{001}=19.2$ $\mathrm{nm}$, was obtained from Southern clay Products Co, USA, with trade name Cloisite 10 A. A nonconventional wood, Veneer, was collected from the local forest of Senegal. Other reagents were used without further purification. The HDPE/OMMT nanocomposites were prepared by melt mixing in a Brabender Plasticorder mixing chamber (model W $50 \mathrm{EHT}$ ) having the following characteristics: chamber volume of $55 \mathrm{~cm}^{3}$, sample weight of $40-70 \mathrm{~g}$, maximum couple of $200 \mathrm{Nm}$ and maximum temperature of $500^{\circ} \mathrm{C}$. Prior mixing, the EGMA compatibilizer and the nano filler were dried at $80^{\circ} \mathrm{C}$ for $24 \mathrm{~h}$. All the ingredients were mixed simultaneously. The major processing parameters were temperature, screw speed and mixing time; they were set at $180^{\circ} \mathrm{C}, 50 \mathrm{rpm}$ and $10 \mathrm{~min}$, respectively. The processed material was granulated, and then subjected to 4 repeated cycles under the same operating conditions. For each cycle, a part of resulting material was compressed to produce thin films of an average thickness of $150 \mu \mathrm{m}$ with the aid of hydraulic press equipped with two heated plates at $200^{\circ} \mathrm{C}$ with a pressure of 30 bars. Various formulations based on HDPE were prepared and their codes and compositions are listed in Table 1 below.

\subsection{Morphological Characterization}

The morphology of the fracture surface of the impacted samples, after coating with a thin layer of gold, was investigated by KYKY-2800B type scanning electron microscope (Travor-Northern, USA). The crystals' morphology of transcrystallinity was performed on the polarized optical microscopy (Yongheng 59XA, China) with a digital camera system (Panasonic wv-CP240, Japan). Samples were pressed between two glass slides with a distance of about $100 \mu \mathrm{m}$ and first melted on a hot stage at $260^{\circ} \mathrm{C}$ for $10 \mathrm{~min}$, and then cooled to room temperature at a cooling rate of $18^{\circ} \mathrm{C} / \mathrm{min}$, taking micrographs of the growing crystal at selected times. The major issues during these examinations (SEM) are the dispersion of the wood's particle and clay nano particles within the

Table 1. Composition and code of the samples (percentage is in weight).

\begin{tabular}{ccccc}
\hline Sample code & HDPE (\%) & Wood (\%) & Nanoclay (\%) & EGMA (\%) \\
\hline HDPE & 100 & 0 & 0 & 0 \\
PEG & 97.5 & 0 & 0 & 2.5 \\
PEN & 97.5 & 0 & 2.5 & 0 \\
PEGN & 95 & 0 & 2.5 & 2.5 \\
WPE & 50 & 50 & 0 & 0 \\
WPEN & 47.5 & 50 & 2.5 & 0 \\
WPEG & 47.5 & 50 & 0 & 2.5 \\
WPEGN & 45 & 50 & 2.5 & 2.5 \\
\hline
\end{tabular}


polymer matrix, the presence of voids and aggregates, as well as the interfacial adhesion between the nano fibers and the polymer matrix and to investigate the possible interfacial interactions between the polymer and the cellulose nano fibers. In fine details, the study of the dispersion of nanoclay in WPCs was performed by using transmission electron microscope (JEM-100 CX II) at an accelerated voltage of $20-100 \mathrm{kV}$.

\subsection{Rheological Characterization}

Melt rheological measurements of neat PE and wood PE composites were carried out in a nitrogen atmosphere at $180^{\circ} \mathrm{C}$ with a parallel plate rheometer. The gap was adjusted to $1.5 \mathrm{~mm}$ and then the squeezed molten material was carefully trimmed off for attaining smooth edge surface. The rheological properties of the wood polymer composite melts were measured at $180^{\circ} \mathrm{C}$; the frequency was ranged from $0.1 \mathrm{rad} / \mathrm{s}$ to $100 \mathrm{rad} / \mathrm{s}$. The imposed oscillatory shear strain amplitude was tested for each temperature to valid all the measurements inside the linear viscoelastic domain. Strain sweep was performed with polyethylene sample and was kept at $1 \%$ in all composite samples frequency scans. The sample was pre stretched with a strain rate of $0.04 \mathrm{~s}^{-1}$ to remove sagging. Then, it was left in the fixture for $3 \mathrm{~min}$ to relax any accumulated stress before the start of the experiment. Viscosity is one of the most commonly used parameters to investigate the behavior of polymer materials during processing, since the majority of transformation processes occur in shear flows. The great length of polymer chains results in extensive entanglements and complicates the study of neat polymer flow [41]. When an oscillatory strain is applied, the resulting stress is measured. By the deconvolution of the stressstrain rate in-phase and the out-of phase components, both real part and imaginary one of the complex shear viscosity $\eta_{(\omega)}^{*}$ can be determined by the following Equation (1).

$$
\eta_{(\omega)}^{*}=\eta_{(\omega)}^{\prime}-j \eta_{(\omega)}^{\prime \prime}
$$

where $\eta^{*}$ is the complex viscosity, $\eta^{\prime}$ is the loss viscosity and $\eta^{\prime \prime}$ is the storage one.

$\omega$ is the pulsation of the frequency $(N)$; it is indicated in Equation (2):

$$
\omega=2 \pi N
$$

Then, the real component of the complex viscosity $\left(\eta^{\prime}\right)$ describes the viscous dissipation in the sample, while the imaginary component $\left(\eta^{\prime \prime}\right)$ represents the stored elastic energy. Furthermore, the tangent of the phase angle $(\tan \delta)$ describes the balance between the viscous and elastic behaviors in a polymer melt (Equation (3) below):

$$
\tan \delta=h^{\prime} / h^{\prime \prime}
$$

Another useful representation is to plot the experimental frequency sweep data points in the complex plane. That means that imaginary part (of the complex viscosity) $\eta^{\prime}$ values are reported along the abscissa (X axis) and the imaginary ones $\left(\eta^{\prime \prime}\right)$ in ordinate (Y axis). Usually, the experimental points are located on arc of circle characteristic for a Cole-Cole distribution. The extrapolation of this arc of circle to the zero ordinate value gives the Newtonian viscosity which is related to the average molecular weight $\mathrm{Mw}$ of the considered polymer through a power law (Equation (4) below): 


$$
\eta_{0}=K \cdot(M w)^{3.4}
$$

\subsection{Thermal Stability Characterization}

Thermal gravitational analysis (TGA) provides quantitative information on weight change process while differential thermal gravimeter (DTG) provides the rate of weight loss (dW/dt).

Thermal behavior of the matrix, wood fiber (WF) and composites was investigated by thermogravimetric analysis under nitrogen at a heating rate of $10^{\circ} \mathrm{C} / \mathrm{min}$, from $30^{\circ} \mathrm{C}$ to $500^{\circ} \mathrm{C}$.

The sample (masse of $10 \pm 1 \mathrm{mg}$ ) was placed in a little cup made of aluminum hanging from a microbalance. The variation of the mass of the sample allows drawing the TG (variation of the mass in function of the temperature) and DTG (derivative of loss of mass versus the time) thermograms. The combination of these two thermograms gave a clear indication of number of stages of the thermal degradation. This method allows determining the degradation temperature of the materials and thus the thermal stability of the composite.

\section{Results and Discussions}

\subsection{Morphological Characterization}

Wood fiber (Veneer) was employed as reinforcement material in thermoplastics industry due to its higher fiber aspect ratio compared to wood flour [42]. The SEM micrographs displayed in Figure 1(a) showed that the elements (HDPE and Wood), initially are quite immiscible as judged by the separation of different phases. These SEM micrographs present outer surfaces of wood fibers surrounded by some amorphous lignin reflecting a typical morphology of a binary mixture of HDPE and Wood. It shows large wood fibers with poor interfacial adhesion and dispersion in the polymer matrix. From

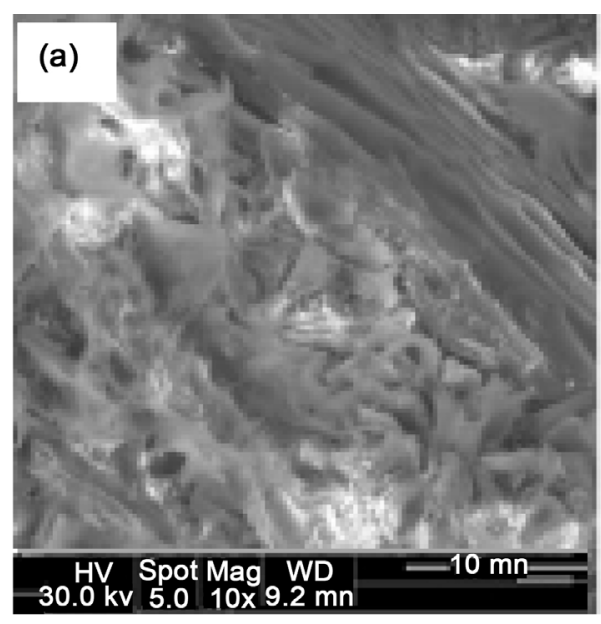

WPE

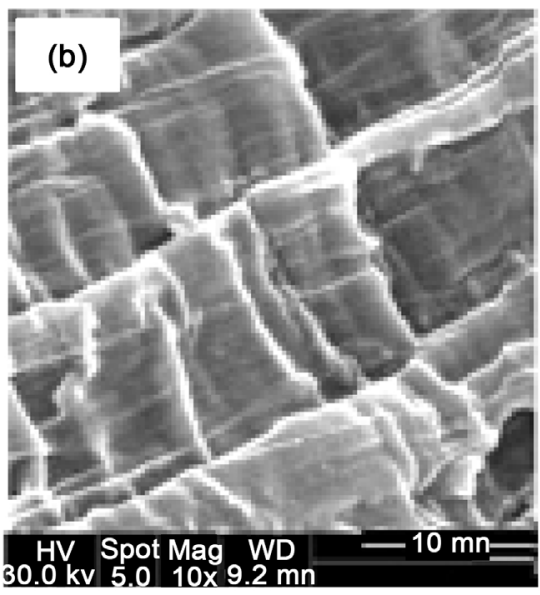

PEN

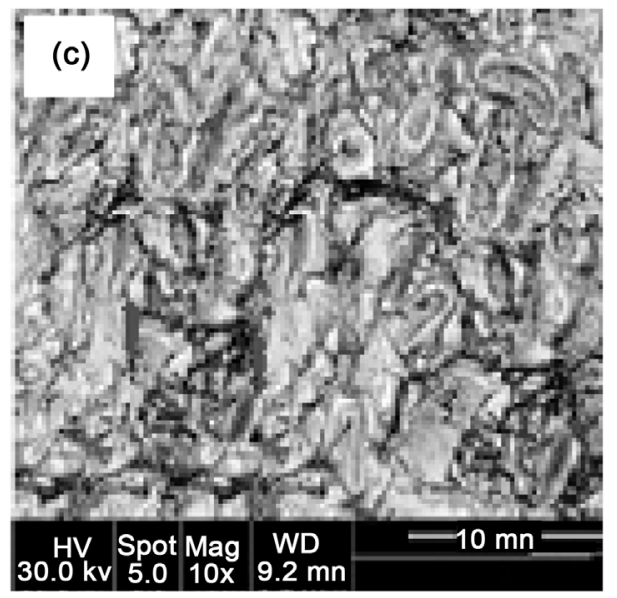

WPEN

Figure 1. SEM images of HDPE composites: (a) HDPE/Wood (WPE); (b) HDPE/Nanoclay (PEN); and (c) HDPE/Wood/Nanoclay (WPEN). 
the SEM micrographs of sample (HDPE/Wood) in Figure 1(a) with the high percentage of wood (50\%), it can be observed that the matrix coverage was insufficient and many voids appeared leading to weak interfacial adhesion. This image corresponds to WPC without any coupling agent which shows some evidence of fiber pull out from matrix. This indicates that the level of interfacial bonding between the reinforcing agent and polymer matrix in the composites without coupling agent is weak. Therefore when stress is applied it causes the fibers to be leave the matrix easily and makes gaping holes. In Figure 1(b) (97.5\% HDPE + 2.5\% Clay), the existence of the clay aggregates can be seen at the micrometer level, and therefore, the morphology is not homogeneous, which reveals a poor intercalated/exfoliated structure. In other words at higher wood (50\%) loading, agglomeration takes place and the applied load will be distributed unevenly between non-agglomerated and agglomerated wood particles. In this Figure 1(b), small stacks of silicate layers connected in the polymer phase can be observed in these images. They appear to be completely exfoliated and seem to "flow" with the polymer. The SEM nanograph of the samples exhibit visible nanoparticles; this is a typical effect for the inclusion of nano fillers in a polymer structure. In Figure 1(c), the incorporation of filler into the polymer matrix disrupted the homogeneity of the matrix. Particles did not adhere very well to the surface of polymeric matrix that cracks and voids can be observed around the particles clearly. It can be seen some cavities in the surface that can absorb water and/or reduce mechanical properties. Sun S. et al. [43] reported that the tensile strength of composites is mainly influenced by filler fraction and the interfacial adhesion between particles and matrix. The possible reason proposed for this kind of behavior may be the better interfacial adhesion between the matrix and wood fiber. In the presence of MAPE EGMA, there are fewer fiber pullouts from the matrix compared to the HDPE/wood composites and no sign of fiber agglomeration are observed.

For the blends containing HDPE/ EGMA (Figure 2(a)), we can see that the composite phase appears as regular and the blend look more uniform. The results suggest a smooth clean surface, which would promote interfacial adhesion between the two elements. From the images of Figure 2, the smooth surface of the HDPE/EGMA (Figure $2(a))$ is contrasted against the textured surface of the samples with wood (Figure 2(b) and Figure 2(c)). Figure 2(b) (HDPE/Wood/EGMA) shows that the polymer is well
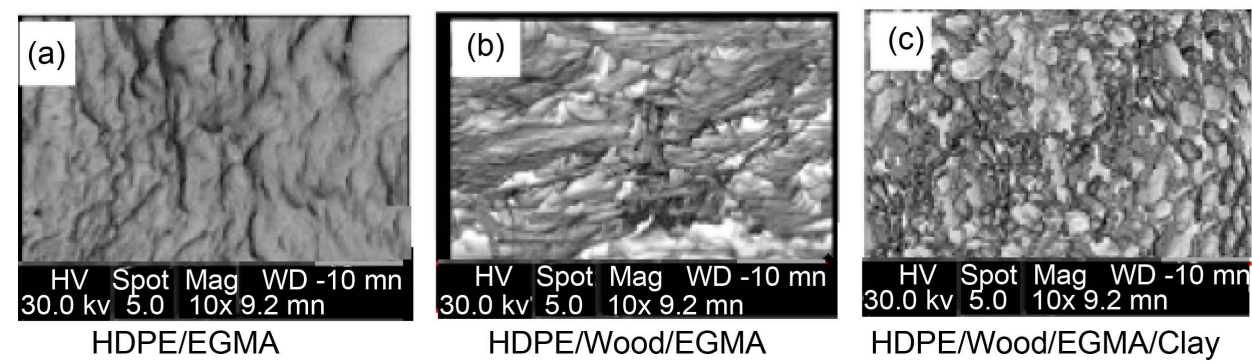

Figure 2. SEM images of HDPE composites: (a) HDPE/EGMA (PEG); (b) HDPE/Wood/EGMA (WPEG); and (c) HDPE/Wood/EGMA/Clay (WPEGN). 
spread over the surfaces of the wood chips in the compatibilized composite. For the blend containing HDPE/Wood/Clay/EGMA (Figure 2(c)), the reinforcements are dispersed as nodules in the polymers matrix and the dispersion is irregular. When the compatibilizer (EGMA) was added, it was observed that the density and size of the aggregates decreased, which indicates that the dispersion of nanoclay within the polymer matrix is much better. In this Figure 2(c), the fiber is little pulled-out compared to Figure 1(c) because contact between the matrix and the fibers is improved with the addition of EGMA compatibilizer [44]. The reason for this is that EGMA reacts with WF, decreasing its surface energy and its hydrophilicity. In this last figure, it is possible to observe, the shiny particles of wood with different sizes, inhomogeneous parts. With the relatively high rate of wood $(50 \%)$, it is difficult that the polymer completely encapsulates the wood. The porosity of a composite material can change its mechanical behavior significantly. Besides their influence on the volume ratio of reinforcing, the presence of large pores may result in early failure of the material, or reduce its rigidity. When EGMA is present, as can be seen, there is few separation of the fibers from the matrix and good interaction between the components can be inferred from the image. The strong adhesion that is observed at the interface has been affected to the coupling agent, which stimulates the polymer encapsulating the wood and caused strong bonding. Better adhesion results into more restriction to deformation capacity of the matrix in the elastic zone and increased modulus. Similar observations were reported for other lignocellulosic fibers based HDPE composites [45]. According to these results, composite having (EGMA) coupling agent provided smoother surfaces than those without coupling agent. To compare the effect of EGMA (Figure 2(b)) with that of clay (Figure $1(c)$ ), it can be seen that in the presence of EGMA, increased interfacial adhesion was observed between the fibers and the HDPE matrix. In fiber composites with clay and without EGMA (Figure 1(c)), the matrix was not attached to the surfaces of the fibers, and some fibers were pulled out from the matrix, thus indicating a weak interfacial bonding. The addition of $2.5 \%$ EGMA to the composite increases bulk consistency. In conclusion, it is visible from this work that WPECs produced with adding EGMA had considerably fewer holes and many broken fiber ends embedded in the polymer matrix, indicating better compatibility between the wood flour and the polymer matrix. In the control WPECs, several holes were observed. These defects appeared to result from the fiber pulling out from the matrix, indicating poor bonding between the wood flour and the polymer matrix (Figure 1(a)). To see more images in fine detail, a polarized light transmitted through a polarized light microscopy is used (Figure 3).

In Figure 3, are shown the morphologies of neat HDPE and composite (HDPE/ Wood/EGMA/Clay). We have only shown these two cases because the other composites exhibit a similar morphology to the second image, namely, an increase in the number of small crystals. This is clearly illustrated by the presence of debonding areas. Amorphous and crystalline parts form superstructures called spherulites are observed. This increase in the number of spherulites (in the composite) can be attributed to the effect of the nucleating timber plays by wood. These regular images are separated by 

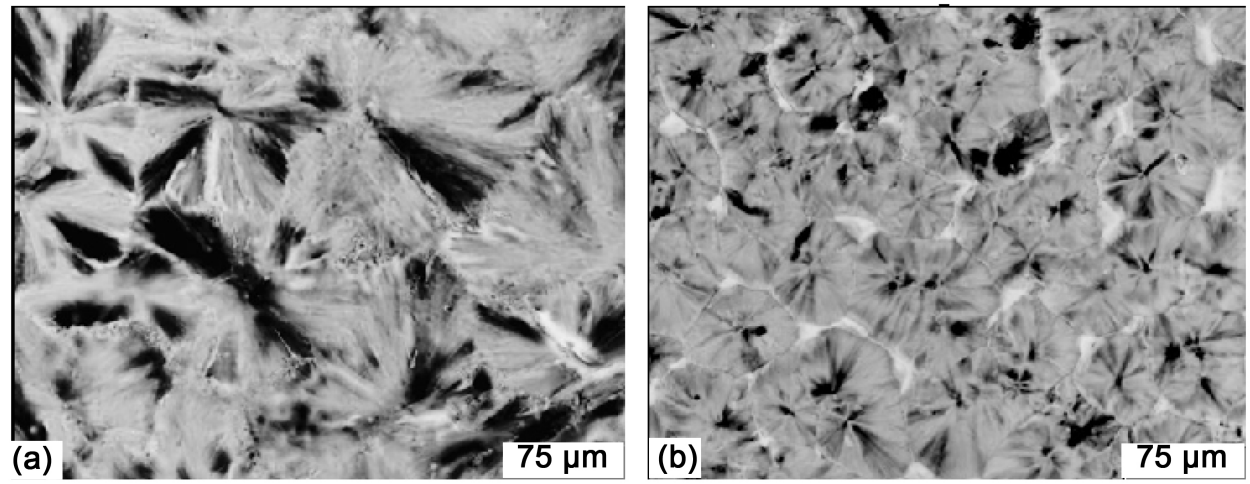

Figure 3. Crystal morphology of neat HDPE (a) and HDPE/Wood/clay/EGMA (b).

visible lines especially in the second figure. An agglomeration of the nanoparticles was visible, this agglomeration occurred due to the surface interaction among the nanoparticles. Surface modification is crucial in ensuring excellent interfacial adhesion between the polymeric matrix and wood. A strong interfacial bonding between the reinforcement and the matrix enhances the properties of the resultant composites by facilitating good load transfer between the matrix and the reinforcing filler. These are key requirements for the application of wood as fillers in polymers.

\subsection{Rheological Behavior}

Rheological behavior of polymeric melts is an important aspect to understand the flow behavior of the materials during processing.

Figure 4 showed the variation of complex viscosity with frequency for the wood fiber/HDPE composites. It was well established that the addition of filler into the polymer matrix increased the viscosity of the melt. The rigid fiber particles may disturb the flow and provide obstruction to flow of the polymer melt, thus causing a rise in viscosity. The increased viscosity depends on the concentration, particle size distribution and shape of the fillers.

Figure 4 shows the rheological curves of different melts at $240^{\circ} \mathrm{C}$ in the plot of apparent viscosity versus shear rate. Clearly, the apparent viscosity decreases significantly as shear rate increases for all the blends. The incorporation of wood and clay particles in polymeric matrix modifies their rheological properties. The filler-polymer interactions result in an increase of the complex viscosity, especially at low frequencies, and thus conduct to a more pronounced shear thinning behavior. The HDPE composites reinforced with clay or EGMA showed the highest melt viscosity. The introduction of EGMA to the system increased the flow behavior of the polymer, and dispersed the fiber uniformly in the system, which decreased the melt viscosity. The viscosity of composite reinforced with only wood fiber was lower than that of the treated composites, that maybe due to the weak interfacial bonding strength between the fiber and matrix. The obtained results proved that the presence of the coupling agent EGMA improved the dynamic behavior of the materials by strengthening the fiber/matrix interface. The evolution of the viscosity of the composite as a function of fiber content has a nonlinear 


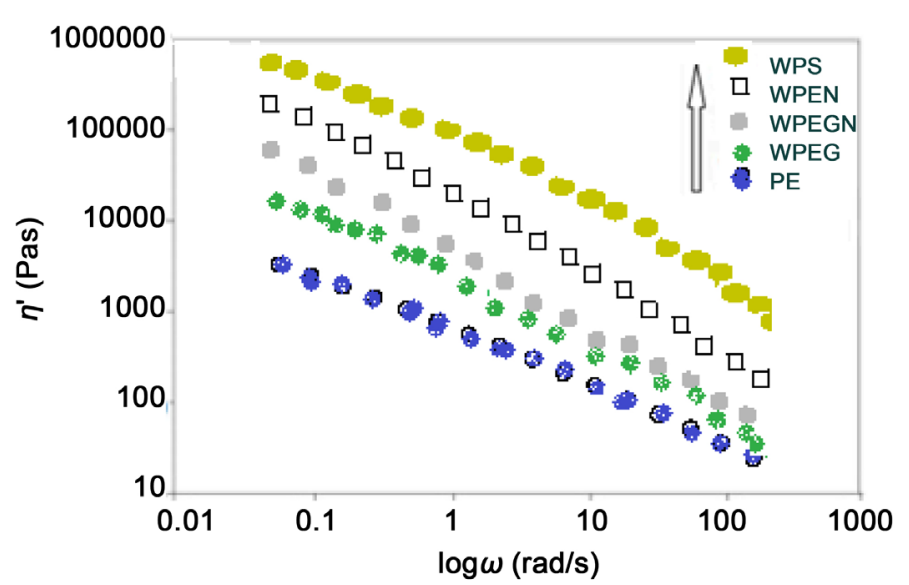

(a)

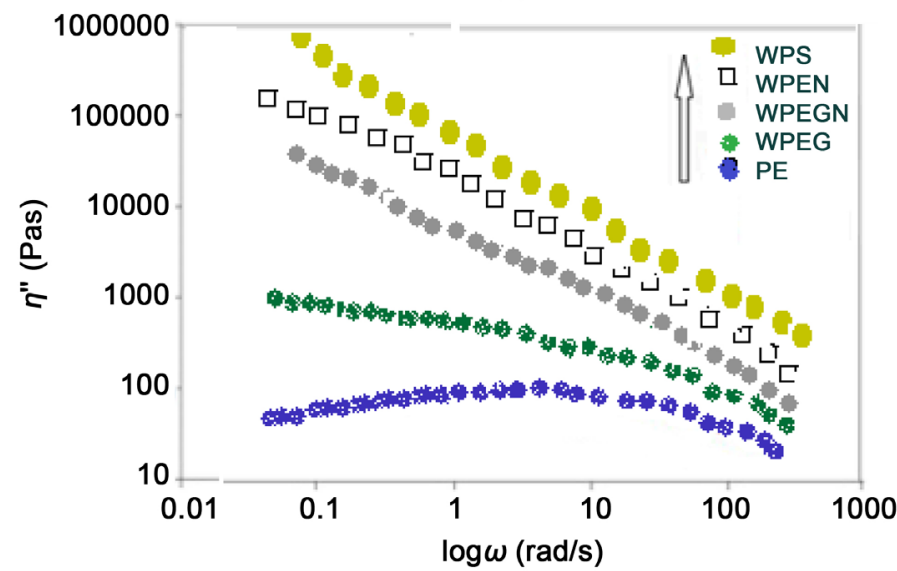

(b)

Figure 4. Frequency variations of the loss $(\eta)$ and the storage $\left(\eta^{\prime \prime}\right)$ viscosities for neat $\mathrm{HDPE}$ and its composites at $\mathrm{T}=180^{\circ} \mathrm{C}$.

behavior. At low frequencies, the viscosity increases greatly when fiber content and/or coupling agent is present. The melt viscosity decreased with increasing frequencies indicating the pseudo plastic nature of the blends. The addition of fillers influences density, stiffness and viscoelastic behavior of a polymer. The highest complex viscosity was related to the composite (WPE) containing 50\% wood. In addition, the presence of agglomerates (due to high filler load) caused resistance against the flow and increased viscosity of composites. All the dynamic viscosity decreases showing shear thinning behavior as previously observed in other filler melts [46] [47]. This behavior can be attributed to the higher degree of polymer-filler interaction, which requires higher shear stress and longer relaxation times for the composites to flow [48]. Regarding the rheological properties, both the composites and pure polyethylene exhibit typical shearthinning behavior.

This Table 2 reports the Newtonian values determined for all the samples: WPE exhibits the higher viscoelastic behavior but it contains 50\% wood filler and 50\% PE matrix while samples WPEN and WPEG contain only 45\% PE matrix and 50\% Wood filler. Thus in the second case the ratio matrix/filler is less than $1(0.9)$ while it is 1 in the 
Table 2. Newtonian values of WPC composites.

\begin{tabular}{cccccc}
\hline Sample & PE (\%) & Wood (\%) & EGMA (\%) & Clay (\%) & $\eta_{0}(\mathrm{~Pa} \cdot \mathrm{s})$ \\
\hline HDPE & 100 & 0 & 0 & 0 & 3600 \\
WPE & 50 & 50 & 0 & 0 & $\infty$ \\
WPEN & 45 & 50 & 0 & 5 & 212,000 \\
WPEG & 45 & 50 & 5 & 0 & 265,000 \\
\hline
\end{tabular}

first case. If we compare samples with the same ratio (WPEN and WPEG) we can notice that the higher Newtonian viscosity is obtained with the sample containing EGMA as comptabilizer, then the addition of a small concentration of nanoparticles like nanoclay does not improve the resulting melt viscoelastic behavior of the wood polymer composite.

Figure 5 represents the complex plane variations for the neat HDPE and the wood polyethylene composites. Again great changes are observed for WPE regarding the reference of HDPE. However, for samples WP, WPEG and WPEC the circular variation seems still quite valid. Sample WPE exhibits a deviation to the circular behavior and shows a linear variation of the storage viscosity versus the loss viscosity. This is characteristic for a gel behavior indicating then a high level of interaction between the matrix and the filler however no compatibilizer is used. As observed from the SEM micrographs, at this higher wood (50\% weight) content there is not enough EGMA to completely cover the fibers, thus there is probably a stronger interaction between HDPE and wood. The compatibilizer, PE-co-GMA, increased the interfacial adhesion between wood and HDPE by its glycidyl linkage and long olefinic chain and thus performed a number of properties.

\subsection{Thermogravimetry Analysis}

The thermal degradation of Wood fiber and neat HDPE as a function of temperature is shown in Figure 6(a). The pure polymer shows a negligible mass loss at temperatures lower than $400^{\circ} \mathrm{C}$. The significant decrease of the mass loss begins around $450^{\circ} \mathrm{C}$. The TGA of the wood fiber shows a two-step degradation process with an initial transition around $100^{\circ} \mathrm{C}$ due to moisture evaporation. Cellulose is the main constituent of the cell wall of several lignocellulosic fibers. It is established in wood that the cellulose contains numerous hydroxyl groups that are strongly hydrophilic. The initial degradation temperature $\left(\mathrm{T}_{\mathrm{d}}\right)$ of the wood veneer was $250^{\circ} \mathrm{C}$ and the decomposition peak temperature appeared at $351^{\circ} \mathrm{C}$. However in other samples (Figure $6(\mathrm{~b})$ ), in both cases, a decrease in weight loss below $100^{\circ} \mathrm{C}$ was observed which was due to the removal of moisture. Because of high inflammability of cellulose, the addition of wood makes the composite less thermally stable. The TGA measurements indicate that when the polymer is heated, its thermal stability is usually appraised from the loss of mass and its molecular weight sharply diminishes due to the degradation of the molecular chains [49]. Loss of material due to the degradation of wood occurs mainly after $220^{\circ} \mathrm{C}$ for wood. The increase in decomposition temperature is attributed to the hindered diffusion (i.e. barrier effect) of 


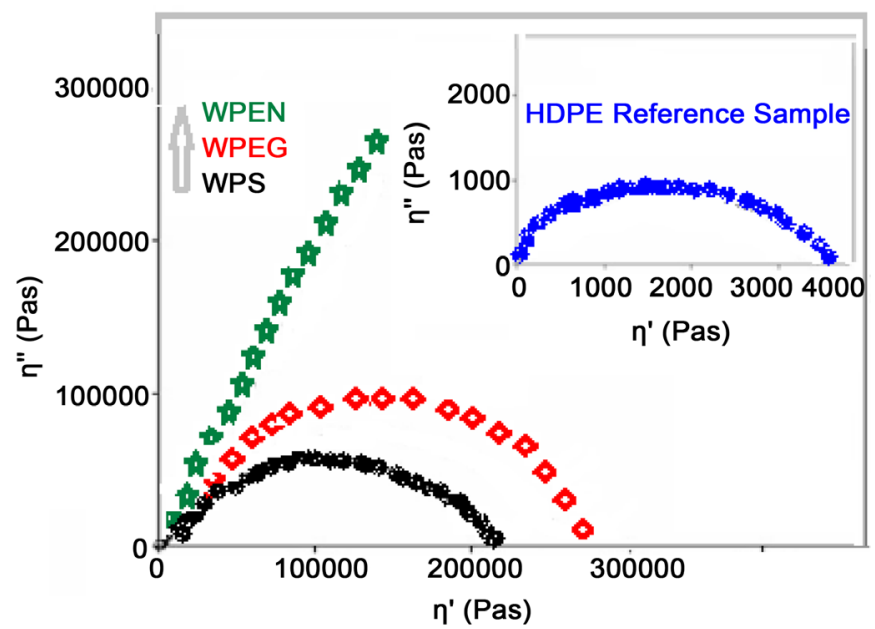

Figure 5. Complex plane diagrams for the WPC (upper right curve for neat HDPE) at $\mathrm{T}=180^{\circ} \mathrm{C}$.

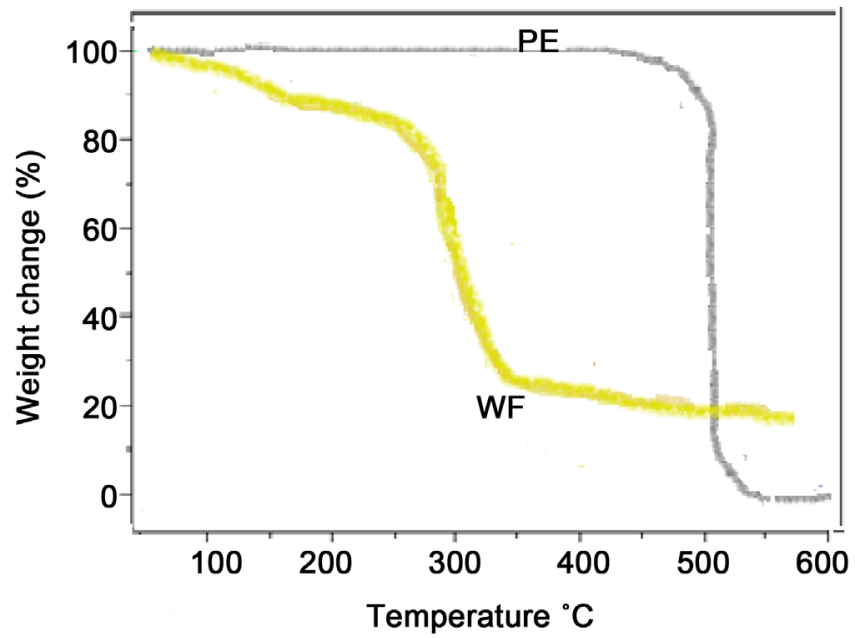

(a)

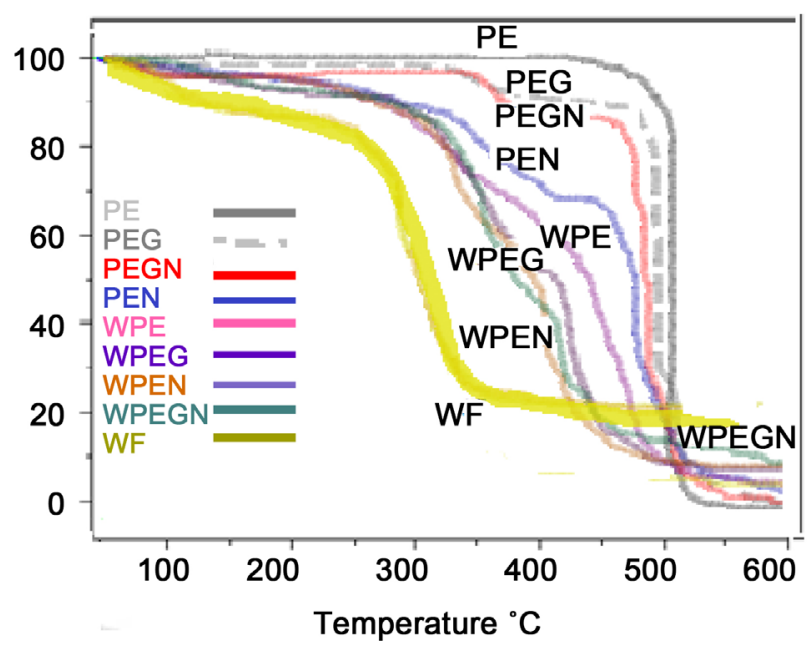

(b)

Figure 6. TGA thermograms of neat HDPE and its composites. 
volatile decomposition products caused by the dispersed clay particles in the polymer matrix [50]. The main degradation peak at $360^{\circ} \mathrm{C}$ corresponds to cellulose degradation, while the shoulder at the lower temperature $\left(345^{\circ} \mathrm{C}\right)$ can be attributed mainly to hemicelluloses degradation [51]-[53]. The degradation mechanism of the Wood/HDPE composites is not yet well understood. However, possible reasons for the increase in thermal stability of these blends may be that the wax crystals in the amorphous phase of the polymer are initially protected by the surrounding polymer chains. Also, in the case of neat HDPE, the degradation began around $450^{\circ} \mathrm{C}$, and the maximum decomposition rate appeared at $490.5^{\circ} \mathrm{C}$. The degradation temperature range (around $450^{\circ} \mathrm{C}$ ) of this polymer moved to lower temperatures, in the composite with and without coupling agent remained the same, this indicates that the coupling agent (EGMA or Clay) more probably initiated grafting between the polymer and the fiber, which reduced the number of tertiary carbon atoms in the polymer and its subsequent degradation. The initial decomposition temperature for the composite is typical of wood, in which pyrolysis of wood components took place below $250^{\circ} \mathrm{C}$. The important degradation process of wood starts at around $200^{\circ} \mathrm{C}-220^{\circ} \mathrm{C}$ and it concerns the three major constituents of wood (cellulose, hemicellulose and lignin). The addition of compatibilizer had little influence on the decomposition behavior of Wood/HDPE composite containing $2.5 \%$ clay. It is clear that the decomposition temperature of the nanocomposite shifted towards higher temperatures, indicating higher thermal stability of the material with $5 \mathrm{wt} \%$ clay. The existence of inorganic materials in polymer matrix, generally, enhances the thermal stability of the nanocomposite. The TGA results showed that all the composite samples were thermally less stable than the neat matrices, and the composite with EGMA were thermally less stable than the other ones. All clay composites showed improved thermal stability compared to the other ones without clay. Giannelis et al. [3] attributed this increased thermal stability to the hindered diffusion of the volatile decomposition products. An increase in decomposition temperature for all composites compared to neat HDPE was observed. The addition of $2.5 \%$ clay slightly lowered the $\mathrm{T}_{\mathrm{d}}$ and the first decomposition peak temperature of HDPE/wood composite possibly because of the release of the low-molecular-weight compounds with which the clay was treated to become organic, and the increased residue weight was due to the inorganic compounds in clay. An increase in interfacial adhesion between the fibres and the matrix increased the thermal stability and decreased the percentage of weight loss. This result indicates a significant effect on the thermal stability of the composites after incorporating additives. Table 3 shows the initial decomposition temperature $\left(\mathrm{T}_{\mathrm{d}}\right)$, maximum pyrolysis temperatures, and residual weight (RW, \%) for neat HDPE and its composites.

We can conclude that the first decomposition step at $100^{\circ} \mathrm{C}$ corresponds to the evaporation of moisture in the composites. The second step at $262^{\circ} \mathrm{C}$ corresponds to the degradation of cellulose. The third step at $352^{\circ} \mathrm{C}$ is a combination of the degradation of cellulose and others elements. The fourth step at $400^{\circ} \mathrm{C}$ is due to the degradation of the unsaturated and saturated carbon atoms of HDPE. At $480^{\circ} \mathrm{C}$, char formation is observed for Wood/HDPE/composites. The thermal degradation of WPE and WPEN was 
Table 3. Degradation characteristics of neat HDPE and its composites.

\begin{tabular}{ccccc}
\hline \multirow{2}{*}{ Sample } & $\mathrm{T}_{\mathrm{d}}\left({ }^{\circ} \mathrm{C}\right)$ & \multicolumn{2}{c}{ Peak temperature $\left({ }^{\circ} \mathrm{C}\right)$} & Residue (\%) \\
\cline { 3 - 4 } & & Peak I & Peak II & 0.0 \\
HDPE & 450.0 & - & 490.5 & 15.5 \\
Wood & 250.0 & 351.0 & - & 5.8 \\
WPE & 265.5 & 352.5 & 467.5 & 6.5 \\
WPEN & 262.7 & 351.4 & 470.5 & 6.5 \\
WPEG & - & 360.0 & 480.0 & 6.5 \\
WPEGN & 262.0 & 352 & 472.0 & \\
\hline
\end{tabular}

mainly composed of two steps. The first peak temperature (Peak I) of WPEN was lower than that of WPE, while the second peak temperature (Peak II) of WPEN was higher (Table 3), indicating that the incorporation of clay significantly accelerated the decomposition of the WPEN, which was consistent with the findings of a previous study of Delobel et al. [54]. The incorporation of nanoclay improved the thermal stability of HDPE/WF nanocomposite [55]. The tortuous path provided by the silicate layers had better barrier property to the oxygen and heat which delayed the burning capacity of the composite. Guo et al. [56] observed that the flame retardancy of wood fiber-plastic composite increased after the incorporation of nanoclay.

\section{Conclusion}

It was observed from the SEM micrographs that modifying matrix with the PE (EGMA), the composite shows homogeneity; adhesion is better; and the surface of the composite is smooth in comparison with the uncompatibilized ones. This shows that the compatibilizer promotes interfacial adhesion between polymer matrix and WF. The introductions of wood fibers lead to more bridges formation via ester links which increased the efficiency of the impact force transfer. The composite of HDPE and wood is thermally less stable than the neat HDPE. It was found that the addition of 2.5\% EGMA not only improved the dispersion of NC concentrate particles but also increased the wettability between NC and matrix evidenced by the absence of clustered NC particles. The TGA results showed that all the composite samples were thermally less stable than the neat matrix and the composites with EGMA were thermally less stable than the other ones. An increase in decomposition temperature for all composites compared to neat HDPE was observed. The incorporation of wood and clay particles in polymeric matrix modifies their rheological properties. The filler-polymer interactions result in an increase of the complex viscosity, especially at low frequencies, and thus conduct to a more pronounced shear thinning behavior. Increasing content of wood fiber in composites causes the sufficient increase in their dynamic viscosities. This can be explained by both inhomogeneous dispersion and aligning of cellulose phase in composites and/or perturbation of normal polymer flow and breaking the mobility of chain segments due to the presence of cellulose particles. This can be explained by both inhomogeneous 
dispersion and aligning of wood fiber phase in composite or a disturbance of normal polymer flow which generates the rupture of the chain segments of mobility due to the presence of wood particles in the form of aggregates. It was found that both blends show pseudo plastic. Melt viscosity of WPC blends was sensitive to shear rates. The complex viscosities were quite high at the low frequency but decreased with increasing frequency indicating a shear thinning behavior of the wood fiber composites. The rheological properties were improved by the incorporation of EGMA or clay. The quality of dispersion was improved by the incorporation of PEGMA as the compatibilizer. This is due to the fact that PE-EGMA helps polymer chains to penetrate the zones of the organoclay easily. It was also found that using lignocellulosic as filler in polypropylene composites resulted in higher mixing due to increase in viscosity. The complex viscosity decreased with increasing oscillation frequency, enhancing the fluidity of the samples, because of thinning effect. The melt-flow index results show values lower than expected, also corroborating the possible formation of filler agglomerates in the composite. All these results indicate that adding coupling agent (EGMA or clay) is an effective method to improve the processability of HDPE wood composite.

\section{Acknowledgements}

The authors wish to thank the African Center of Excellence in Mathematics, Computer Science and Technology of Information and Communication (CEA-MITIC) of Gaston Berger University for supporting a part of the research program.

\section{References}

[1] Cheng, J.J. (2008) Mechanical and Chemical Properties of High Density Polyethylene: Effects of Microstructure on Creep Characteristics. Doctoral Thesis, University of Waterloo, Canada.

[2] Giannelis, E.P., Krishnamoorti, R. and Manias, E. (1999) Polymer-Silicate Nanocomposites: Model Systems for Confined Polymers and Polymer Science. Advances in Polymer Science, 138, 107-147. http://dx.doi.org/10.1007/3-540-69711-X_3

[3] Giannelis, E.P. (1998) Polymer-Layered Silicate Nanocomposites: Synthesis, Properties and Applications. Applied Organometallic Chemistry, 12, 675-680. http://dx.doi.org/10.1002/(SICI)1099-0739(199810/11)12:10/11<675::AID-AOC779>3.0.CO $\underline{; 2-\mathrm{V}}$

[4] Xu, R., Manias, E., Snyder, A.J., et al. (2001) New Biomedical Poly(Urethane Urea) Layered Silicate Nanocomposites. Macromolecules, 34, 337-339. http://dx.doi.org/10.1021/ma0013657

[5] Gilman, J.W. (1999) Flammability and Thermal Stability Studies of Polymer Layered-Silicate (Clay) Nanocomposites. Applied Clay Science, 15, 31-49. http://dx.doi.org/10.1016/S0169-1317(99)00019-8

[6] Sinha, R.S., Yamada, K., Okamoto, M., et al. (2002) New Polylactide/Layered Silicate Nanocomposite: A Novel Biodegradable Material. Nano Letters, 2, 1093-1096. http://dx.doi.org/10.1021/nl0202152

[7] Xu, B., Zheng, Q., Song, Y.H., et al. (2006) Calculating Barrier Properties of Polymer/Clay Nanocomposites: Effects of Clay Layers. Polymer, 47, 2904-2910. 
http://dx.doi.org/10.1016/j.polymer.2006.02.069

[8] Sorrentino, A., Tortora, M. and Vittoria, V. (2006) Diffusion Behavior in Polymer-Clay Nanocomposites. Journal of Polymer Science Part B: Polymer Physics, 44, 2665-2674. http://dx.doi.org/10.1002/polb.20684

[9] Hetzer, M. and De Kee, D. (2008) Wood/Polymer/Nanoclay Composite, Environmentally Friendlly Sustainable Technology: A Review. Chemical Engineering Research and Design, 86, 1083-1093. http://dx.doi.org/10.1016/j.cherd.2008.05.003

[10] Song, M., Wong, C.W., Jin, J., et al. (2005) Preparation and Characterization of Poly(Styrene-co-Butadiene) and Polybutadiene Rubber/Clay Nanocomposites. Polymer International, 54, 560-568. http://dx.doi.org/10.1002/pi.1732

[11] Ray, S.S., Yamada, K., Okamoto, M., et al. (2003) Control of Biodegradability of Polylactide via Nanocomposite Technology. Macromolecular Materials and Engineering, 288, 203-208. http://dx.doi.org/10.1002/mame.200390013

[12] Osman, M.A., Mittal, V., Morbidelli, M., et al. (2004) Epoxy-Layered Silicate Nanocomposites and Their Gas Permeation Properties. Macromolecules, 37, 7250-7257. http://dx.doi.org/10.1021/ma048798k

[13] Majumdar, D., Dontula, N., Blanton, T.N., et al. (2003) Smectite Clay Intercalated with Polyether Block Polyamide Copolymer. Europ Patent 1312582.

[14] Principia Partner, Proc. (2003) 7th International Conference on Woodfiber-Plastic Composites (and Other Natural Fibers), USDA Forest Products Laboratory, Madison, Wisconsin.

[15] Faruk, O. and Matuana, L.M. (2008) Nanoclay Reinforced HDPE as a Matrix for WoodPlastic Composites. Composites Science and Technology, 68, 2073-2077.

http://dx.doi.org/10.1016/j.compscitech.2008.03.004

[16] Qiu, W., Zhang, F., Endo, T. and Hirotsu, T. (2005) Effect of Maleated Polypropylene on the Performance of Polypropylene/Cellulose Composite. Polymer Composites, 26, 448-453. http://dx.doi.org/10.1002/pc.20119

[17] Devi, R.R. and Maji, T.K. (2007) Effect of Glycidyl Methacrylate on the Physical Properties of Wood-Polymer Composites. Polymer Composites, 28, 1-5. http://dx.doi.org/10.1002/pc.20265

[18] Dikobe, D.G. and Luyt, A.S. (2007) Effect of Poly (Ethyleneco-Glycidyl Methacrylate) Compatibilizer Content on the Morphology and Physical Properties of Ethylene Vinyl Acetate-Wood Fiber Composites. Journal of Applied Polymer Science, 104, 3206-3213. http://dx.doi.org/10.1002/app.26080

[19] Bledzki, A.K., Gassan, J. and Theis, S. (1998) Wood-Filled Thermoplastic Composites. Mechanics of Composite Materials, 34, 563-568. http://dx.doi.org/10.1007/BF02254666

[20] Faruk, O., Bledzki, A.K., Fink, H.-P. and Sain, M. (2012) Biocomposites Reinforced with Natural Fibers: 2000-2010. Progress in Polymer Science, 37, 1552-1596. http://dx.doi.org/10.1016/j.progpolymsci.2012.04.003

[21] Shih, Y.-F. (2007) Mechanical and Thermal Properties of Waste Water Bamboo Husk Fiber Reinforced Epoxy Composites. Materials Science and Engineering A, 445-446, 289-295. http://dx.doi.org/10.1016/j.msea.2006.09.032

[22] Chen, H., Miao, M. and Ding, X. (2009) Influence of Moisture Absorption on the Interfacial Strength of Bamboo/Vinyl Ester Composites. Composites Part A: Applied Science and Manufacturing, 40, 2013-2019. http://dx.doi.org/10.1016/j.compositesa.2009.09.003

[23] Karmarkar, A., Chauhan, S.S., Modak, J.M. and Chanda, M. (2006) Mechanical Properties of Wood Fibre Reinforced Polypropylene Composites: Effect of a Novel Compatibilizer with Isocyanate Functional Group. Composites Part A: Applied Science and Manufactur- 
ing, 38, 227-233. http://dx.doi.org/10.1016/j.compositesa.2006.05.005

[24] Bledzki, A.K. and Faruk, O. (2003) Wood Fibre Reinforced Polypropylene Composites: Effect of Fibre Geometry and Coupling Agent on Physico-Mechanical Properties. Applied Composite Materials, 10, 365-379. http://dx.doi.org/10.1023/A:1025741100628

[25] Nourbakhsh, A., Kokta, B.V., Alireza, A. and Jahan-Latibari, A. (2008) Effect of a Novel Coupling Agent, Polybutadiene Isocyanate, on Mechanical Properties of Wood-Fiber Polypropylene Composites. Journal of Reinforced Plastics and Composites, 27, 1679-1687. http://dx.doi.org/10.1177/0731684407087377

[26] Lu, J.Z., Wu, Q. and McNabb, H.S.J. (2000) Chemical Coupling in Wood Fiber and Polymer Composites: A Review of Coupling Agents and Treatments. Wood and Fiber Science, 32, 88-104.

[27] Kazayawoko, M., Balatinecz, J.J. and Woodhams, R.T. (1997) Diffuse Reflectance Fourier Transform Infrared Spectra of Wood Fibers Treated with Maleated Polypropylenes. Journal of Applied Polymer Science, 66, 1163-1173. http://dx.doi.org/10.1002/(SICI)1097-4628(19971107)66:6<1163::AID-APP16>3.0.CO;2-2

[28] Zhong, Y., Poloso, T., Hetzer, M. and De Kee, D. (2007) Enhancement of Wood/Polyethylene Composites via Compatibilization and Incorporation of Organoclay Particles. Polymer Engineering \& Science, 47, 797-803. http://dx.doi.org/10.1002/pen.20756

[29] Villar, M.A. and Marcovich, N.E. (2003) Thermal and Mechanical Characterization of Linear Low-Density Polyethylene/Wood Flour Composites. Journal of Applied Polymer Science, 90, 2775-2784. http://dx.doi.org/10.1002/app.12934

[30] Krishnamoorti, E., Vaia, R.A. and Giannelis, E.P. (1996) Structure and Dynamics of Polymer-Layered Silicate Nanocomposites. Chemistry of Materials, 8, 1728-1734.

http://dx.doi.org/10.1021/cm960127g

[31] Dennis, H.R., Hunter, D.L., Chang, D., et al. (2001) Effect of Melt Processing Conditions on the Extent of Exfoliation in Organoclay-Based Nanocomposites. Polymer, 42, 9513-9522. http://dx.doi.org/10.1016/S0032-3861(01)00473-6

[32] Woodhams, R.T., Thomas, G. and Rodgers, D.K. (1984) Wood Fibers as Reinforcing Fillers for Polyolefins. Polymer Engineering \& Science, 24, 1166-1171. http://dx.doi.org/10.1002/pen.760241504

[33] Kazayawoko, M., Balatinecz, J.J. and Matuana, L.M. (1999) Surface Modification and Adhesion Mechanism in Wood Fiber-Polypropylene Composites. Journal of Materials Science, 34, 6189-6199. http://dx.doi.org/10.1023/A:1004790409158

[34] Lacroix, C., Grmela, M. and Carreau, P.J. (1999) Morphological Evolution of Immiscible Polymer Blends in Simple Shear and Elongational flows. The Journal of Non-Newtonian Fluid Mechanics, 86, 37-59. http://dx.doi.org/10.1016/S0377-0257(98)00201-8

[35] Hornsby, P.R. (1999) Rheology, Compounding and Processing of Filled Thermoplastics. Advances in Polymer Science, 139, 156-227. http://dx.doi.org/10.1007/3-540-69220-7_4

[36] Mamunya, E.P., Mishak, V.D., Shumskii, V.F., et al. (1991) Rheological Properties of Polymer-Wood Material Based on Polyethylene. Vysokomolekulyarnye Soedineniya, Seriya B, 33, 839-845.

[37] Xiong, C., Qi, R. and Gong, W. (2009) The Preparation and Properties of Wood Flour/High Density Polyethylene Composites by In-Situ Reaction Extrusion. Polymers for Advanced Technologies, 20, 273-279. http://dx.doi.org/10.1002/pat.1262

[38] Clemons, C. (2002) Wood-Plastic Composites in the United States. Forest Products Journal, 52, 10-18.

[39] Pluart, L.L. and Duchet, J. (2005) Epoxy/Montmorillonite Nanocomposites: Influence of 
Organophilic Treatment on Reactivity, Morphology and Fracture Properties. Polymer, 46, 1267-1278. http://dx.doi.org/10.1016/j.polymer.2005.10.089

[40] Ayak, P.L., Sasmal, A., Nayak, P., et al. (2008) Nanocomposites from Polycaprolactone (PCL)/Soy Protein isolate (SPI) Blend with Organoclay. Polymer-Plastics Technology and Engineering, 47, 600-605. http://dx.doi.org/10.1080/03602550802059402

[41] Kumar, A., Commereuc, S. and Verney, V. (2004) Thermal and Dynamic Mechanical Caracterization of Polypropylene Wood Flour Composites. Polymer Degradation and Stability, 85, 751-757. http://dx.doi.org/10.1016/j.polymdegradstab.2003.11.014

[42] Stark, N.M. and Rowlands, R.E. (2003) Effects of Wood Fiber Characteristics on Mechanical Properties of Wood/Polypropylene Composites. Wood and Fiber Science, 35, 167-174.

[43] Sun, S., Li, C., Zhang, L., Du, H.L. and Burnell-Gray, J.S. (2005) Interfacial Structures and Mechanical Properties of PVC Composites Reinforced by $\mathrm{CaCO}_{3}$ with Different Sizes Ad Surface Treatments. Polymer International, 55, 158-164.

http://dx.doi.org/10.1002/pi.1932

[44] Dikobe, D.G. and Luy, A.S. (2007) Effect of Poly (Ethylene-Co-Glycidyl Methacrylate) Compatibilizer Content on the Morphology and Physical Properties of Ethylene Vinyl Acetate-Wood Fiber Composites. Journal of Applied Polymer Science, 104, 3206-3213. http://dx.doi.org/10.1002/app.26080

[45] Ashori, A. and Nourbakhsh, A. (2011) Preparation and characterization of Polypropylene/Wood flour/Nanoclay Composites. European Journal of Wood and Wood Products, 69, 663-666. http://dx.doi.org/10.1007/s00107-010-0488-9

[46] Qin, H., Zhang, S., Zhao, C., et al. (2004) Thermal Stability and Flammability of Polypropylene/Montmorillonite Composites. Polymer Degradation and Stability, 85, 807-813. http://dx.doi.org/10.1016/j.polymdegradstab.2004.03.014

[47] Sombatsompop, N. and Dangtungee, D.R. (2002) Effects of the Actual Diameters and Diameter Ratios of Barrels and Dies on the Elastic Swell and Entrance Pressure Drop of Natural Rubber in Capillary Die Flow. Journal of Applied Polymer Science, 86, 1762-1772. http://dx.doi.org/10.1002/app.11212

[48] Marcovich, N.E., Reboredo, M.M., Kenny, J. and Aranguren, M.I. (2004) Rheology of Particle Suspensions in Viscoelastic Media. Wood Flour-Polypropylene. Melt. Rheologica Acta, 43, 293-303. http://dx.doi.org/10.1007/s00397-003-0349-0

[49] Ndiaye, D., Badji, A.M. and Tidjani, A. (2014) Physical Changes Associated with Gamma Doses on Wood/Polypropylene Composites. Journal of Composite Materials, 48, 30633071. http://dx.doi.org/10.1177/0021998313506241

[50] Qin, H., Zhang, S., Zhao, C., et al. (2004) Thermal Stability and Flammability of Polypropylene/Montmorillonite Composites. Polymer Degradation and Stability, 85, 807-813. http://dx.doi.org/10.1016/j.polymdegradstab.2004.03.014

[51] Marcovich, N.E., Reboredo, M.M. and Aranguren, M.I. (2000) Modified Woodflour as Thermoset Fillers II, Thermal Degradation of Wood flours and Composites. Thermochimica Acta, 372, 45-57. http://dx.doi.org/10.1016/S0040-6031(01)00425-7

[52] Bouafif, H., Koubaa, A., Perre, P., Cloutier, A. and Riedl, B. (2009) Wood Particle/HighDensity Polyethylene Composites: Thermal Sensitivity and Nucleating Ability of Wood Particles. Journal of Applied Polymer Science, 113, 593-600. http://dx.doi.org/10.1002/app.30129

[53] Martin, A.R., Martins, M.A., Orrfd, S. and Mattoso, L.H.C. (2010) Studies on the Thermal Properties of Sisal Fibre and Its Constituents. Thermochimica Acta, 506, 14-19. http://dx.doi.org/10.1016/j.tca.2010.04.008 
[54] Delobel, R., Bourbigot, S., Le Bras, M., Schmidt, Y. and Leroy, J.M. (1993) Invariant Values of Kinetic Parameters-Evaluation of Fire Retardancy Application to the PPAPP/PER System. Macromolecular Symposia, 74, 59-69.

http://dx.doi.org/10.1002/masy.19930740108

[55] Nourbakhsh, A., Ashori, A., Tabari, H.Z. and Rezaei, F. (2010) Mechanical and Thermo-Chemical Properties of Wood-Flour/Polypropylene Blends. Polymer Bulletin, 65, 691700. http://dx.doi.org/10.1007/s00289-010-0288-8

[56] Guo, G., Park, C.B., Lee, Y.H., Kim, Y.H. and Sain, M. (2007) Flame Retarding Effects of Nanoclay on Woodfiber Composites. Polymer Engineering \& Science, 47, 330-336.

http://dx.doi.org/10.1002/pen.20712

Submit or recommend next manuscript to SCIRP and we will provide best service for you:

Accepting pre-submission inquiries through Email, Facebook, LinkedIn, Twitter, etc.

A wide selection of journals (inclusive of 9 subjects, more than 200 journals)

Providing 24-hour high-quality service

User-friendly online submission system

Fair and swift peer-review system

Efficient typesetting and proofreading procedure

Display of the result of downloads and visits, as well as the number of cited articles

Maximum dissemination of your research work

Submit your manuscript at: http://papersubmission.scirp.org/

Or contact aces@scirp.org 